\title{
DÜBLIN
}

Technological University Dublin ARROW@TU Dublin

\section{New approach of modifying the anatase to rutile transition temperature in $\mathrm{TiO} 2$ photocatalysts}

\author{
Ciara Byrne \\ Institute of Technology, Sligo \\ Rachel Fagan \\ Technological University Dublin \\ Steven Hinder \\ University of Surrey
}

See next page for additional authors

Follow this and additional works at: https://arrow.tudublin.ie/scschcpsart

Part of the Chemistry Commons, and the Nanoscience and Nanotechnology Commons

\section{Recommended Citation}

RSC Adv., 2016,6, 95232-95238

This Article is brought to you for free and open access by the School of Chemical and Pharmaceutical Sciences at ARROW@TU Dublin. It has been accepted for inclusion in Articles by an authorized administrator of ARROW@TU Dublin. For more information, please contact arrow.admin@tudublin.ie, aisling.coyne@tudublin.ie, gerard.connolly@tudublin.ie.

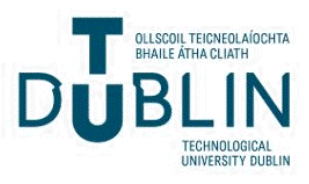


Authors

Ciara Byrne, Rachel Fagan, Steven Hinder, Declan Mccormack, and Suresh Pillai

This article is available at ARROW@TU Dublin: https://arrow.tudublin.ie/scschcpsart/127 


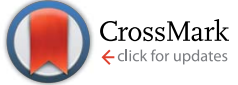

Cite this: RSC Adv., 2016, 6, 95232

\title{
New approach of modifying the anatase to rutile transition temperature in $\mathrm{TiO}_{2}$ photocatalysts $\uparrow$
}

\author{
Ciara Byrne, ${ }^{\text {ab }}$ Rachel Fagan, ${ }^{\text {cd }}$ Steven Hinder, ${ }^{e}$ Declan E. McCormack ${ }^{\text {cd }}$ \\ and Suresh C. Pillai ${ }^{\star a b}$
}

In pure synthetic titanium dioxide, the anatase to rutile phase transition usually occurs between the temperatures of $600{ }^{\circ} \mathrm{C}$ and $700{ }^{\circ} \mathrm{C}$. The phase transition temperature can be altered by various methods, including modifying the precursor or by adding dopant or modifier to the $\mathrm{TiO}_{2}$ sample. In an attempt to investigate the phase transition using aromatic carboxylic acids, the current study examines the impact of increasing concentrations of benzoic acid $(1: 0,1: 1,1: 4$ and 1:8 molar ratio $\mathrm{TiO}_{2}$ : benzoic acid) on anatase to rutile transition. The samples were characterised using Raman spectroscopy, X-ray diffraction (XRD), Fourier transform infrared spectroscopy (FTIR) and X-ray photoelectron spectroscopy (XPS) studies. At $500{ }^{\circ} \mathrm{C}$, all samples contained only anatase. At $600{ }^{\circ} \mathrm{C}$, the $1: 1,1: 4$ and 1:8 samples contain only anatase and the control (which contains no modifier) was a mixture of $27 \%$ anatase and $73 \%$ rutile. At $700{ }^{\circ} \mathrm{C}$, the $1: 1$ molar ratio sample contained $50 \%$ anatase/ rutile, $1: 4$ and 1:8 molar ratio samples were observed to have a majority of anatase, $76 \%$ and $71 \%$ respectively. When the temperature was increased to $800{ }^{\circ} \mathrm{C}$, the sample with the 1:4 molar ratio contained $10 \%$ anatase and at the same temperature the $1: 8$ ratio sample contained $7 \%$ anatase; the remaining samples $(1: 0$ and $1: 1)$ at this temperature contained only rutile. These results show that there is a significant \% anatase still present when the doped samples were calcined to $700{ }^{\circ} \mathrm{C}$ when compared with the control (100\% rutile). There are small amounts of the anatase phase in the $1: 4$ and $1: 8$ samples at $800^{\circ} \mathrm{C}$. Therefore, benzoic acid has induced a delay in the rutile formation.

Received 4th August 2016

Accepted 28th September 2016

DOI: $10.1039 / c 6 r a 19759 k$

www.rsc.org/advances cost, nontoxicity, strong oxidizing ability and long-term stability and large band gap energy. ${ }^{\mathbf{8 - 1 4}}$ The ability of titanium dioxide to act as a photocatalyst is influenced by a number of factors such as phase ratio and purity, particle size, the type of dopant and the concentration of the dopant. ${ }^{12}$

$\mathrm{TiO}_{2}$ occurs in nature in three main polymorphs, ${ }^{5,15-17}$ these are anatase (tetragonal, $a=b=3.785 \AA$ A, $c=9.54 \AA$ ), brookite (orthorhombic, $a=5.143 \AA$, $b=5.456 \AA, c=9.182 \AA$ ) and rutile (tetragonal, $a=b=4.593 \AA$ А $c=2.959 \AA$ ). ${ }^{\mathbf{1 , 5 , 1 0 , 1 1 , 1 5 - 2 4}}$ The $\mathrm{TiO}_{2}$ phases consist of $\left[\mathrm{TiO}_{6}\right]^{2-}$ octahedra that are arranged by sharing edges, corners or both depending on the phase, while maintaining a stoichiometry of $\mathrm{TiO}_{2} \cdot{ }^{10,11,25}$ The rutile phase is identified as the most thermodynamically stable phase, while anatase and brookite are both metastable and can be transformed into rutile irreversibly at elevated temperatures. ${ }^{\mathbf{1 7 , 2 2 , 2 6}}$ This transition temperature is not well defined, however in pure synthetic titanium dioxide, this transition occurs between 600 ${ }^{\circ} \mathrm{C}$ and $700{ }^{\circ} \mathrm{C} .{ }^{13,19}$ Dopants, chemical modifiers and chemical additives can be used in order to improve the photocatalytic activity and alter the transition temperature. ${ }^{8}$

Among the three common titania polymorphs, anatase is considered to be the most photocatalytically active phase.,10,12 An improvement in the amount of anatase phase present at high temperatures $\left(\geq 1000{ }^{\circ} \mathrm{C}\right)$, particularly at the processing

\footnotetext{
University of Surrey, Guildford, Surrey, GU2 $7 \mathrm{XH}$, UK

$\dagger$ Electronic supplementary information (ESI) available. See DOI: 10.1039/c6ra19759k

${ }^{a}$ Nanotechnology and Bio-engineering Research Group, Department of Environmental E-mail: pillai.suresh@itsligo.ie

${ }^{b}$ Centre for Precision Engineering, Materials and Manufacturing Research (PEM), ${ }^{c}$ Centre for Research in Engineering Surface Technology (CREST), FOCAS Institute, Dublin Institute of Technology, Kevin St., Dublin 8, Ireland

${ }^{d}$ School of Chemical and Pharmaceutical Sciences, Dublin Institute of Technology, Kevin St., Dublin 8, Ireland

"The Surface Analysis Laboratory, Faculty of Engineering \& Physical Sciences, 10.1039/c6ra19759k
} 
temperature of ceramic substrates, will be useful for building material applications. ${ }^{10,17}$

In the past, there have been a number of approaches tried to increase the temperature of the anatase to rutile transition to over $700{ }^{\circ} \mathrm{C}^{10,17,27-29}$ One of these approaches includes the use of metal oxide doping. ${ }^{10,17,27-29} \mathrm{Al}_{2} \mathrm{O}_{3}, \mathrm{SiO}_{2}$ and $\mathrm{ZnO}$ are examples metal oxide dopants that have been studied in the past to examine their effect on the anatase to rutile transition. ${ }^{\mathbf{1 0}, 23,28,29}$ While this method can be an effective one, there is one major limitation identified to dope titania samples by using metal oxides. At high temperatures impurities begin to form, for example $\mathrm{Al}_{2} \mathrm{TiO}_{5}$, which results in decreased photocatalytic activity. ${ }^{10,23}$ Instead, non-metal doping (e.g. carbon doping) is examined for increasing the transition temperature. ${ }^{30,31}$ Using carbon as a dopant has shown favourable results for visible light activity when used with $\mathrm{TiO}_{2} \cdot{ }^{22,32-34}$ When the carbon is doped onto the $\mathrm{TiO}_{2}$ it narrows the band gap to $<3.2 \mathrm{eV}$ and improves the photocatalytic activity in the visible region. ${ }^{\mathbf{8 2 2 , 3 5}}$ While nitrogen has been reported to be the most promising non-metal dopant, using carbon has gained interest in recent years. ${ }^{24}$ Hanaor and Sorrell (2011) commented on the fact that there is a lack of reported research on the effects carbon has on the anatase to rutile phase transition. ${ }^{8}$ This is due to the oxidation of carbon at temperatures lower than the transition temperature. They suggested that as carbon is a reducing agent, it would likely to cause the sample to transform to rutile at lower temperatures than normal. ${ }^{8}$ The current paper examines the study of how the addition of various concentrations of an aromatic acid (benzoic acid) affects the anatase to rutile transition in titanium dioxide. X-ray diffraction (XRD) and Raman were employed to determine the \% anatase and/or the \% rutile in the samples. Brunauer-Emmett-Teller method (BET) and scanning electron microscopy (SEM) examined the texture and surface morphology of the samples. While Fourier transform infrared spectrometry (FTIR) and X-ray photoelectron spectroscopy (XPS) were used for determining the bonding involved in the samples.

\section{Experimental}

\section{Materials}

Titanium tetraisopropoxide (97\%), benzoic acid ( $\geq 99.5 \%)$ and isopropanol $(\geq 99.8 \%)$ were purchased from Sigma-Aldrich. When preparing the samples, these were used without additional purification.

\section{Preparation of nanomaterials}

In a typical experiment for the preparation of the $1: 1 \mathrm{TiO}_{2}$ : benzoic acid sample, $25 \mathrm{~mL}$ of titanium tetra-isopropoxide (TTIP) was added to $200 \mathrm{~mL}$ of isopropanol (solution A). $10.31 \mathrm{~g}$ of benzoic acid was dissolved in $100 \mathrm{~mL}$ of isopropanol and this solution was heated until a clear solution was formed (solution B). Solution B was then immediately added to solution A. The mixture was stirred for $5 \mathrm{~min}$ and $150 \mathrm{~mL}$ of deionised water was added, which was then stirred for a further $15 \mathrm{~min}$. This mixture was then aged at room temperature for $30 \mathrm{~min}$. The resulting gel was dried at a temperature of $100{ }^{\circ} \mathrm{C}$ for $24 \mathrm{~h}$. A similar procedure was applied for the preparation of $1: 4$ and $1: 8 \mathrm{TiO}_{2}$ : benzoic acid samples. The powders were calcined at $10{ }^{\circ} \mathrm{C} \min ^{-1}$ to $500{ }^{\circ} \mathrm{C}, 600{ }^{\circ} \mathrm{C}, 700{ }^{\circ} \mathrm{C}, 800{ }^{\circ} \mathrm{C}, 900{ }^{\circ} \mathrm{C}$ and 1000 ${ }^{\circ} \mathrm{C}$, the samples were held at the required temperature for $2 \mathrm{~h}$.

\section{Characterisation}

X-ray diffraction patterns (XRD) for all powder samples (unheated, $500{ }^{\circ} \mathrm{C}, 600{ }^{\circ} \mathrm{C}, 700{ }^{\circ} \mathrm{C}, 800{ }^{\circ} \mathrm{C}, 900{ }^{\circ} \mathrm{C}$ and $1000{ }^{\circ} \mathrm{C}$ ) were obtained using a Siemens D500 X-ray powder diffractometer with a diffraction angle range of $2 \theta=10-80^{\circ}$ using $\mathrm{Cu} \mathrm{K} \alpha$ radiation $\left(\lambda=0.15418 \mathrm{~nm}\right.$ ). The Spurr equation ${ }^{36}$ (eqn (1)) was employed in order determine the quantity of rutile in each of the samples.

$$
F_{\mathrm{R}}=\frac{1}{1+0.8\left[I_{\mathrm{A}}(101) / I_{\mathrm{R}}(110)\right]}
$$

where $F_{\mathrm{R}}$ is the quantity of rutile in mixed sample and $I_{\mathrm{A}}(101)$ and $I_{\mathrm{R}}(110)$ are the intensities of the main anatase and rutile peaks.

For Raman spectroscopy, the Horiba Jobin Yvon LabRAM HR 800 system was used. The grating that was used was $300 \mathrm{~g}$ $\mathrm{mm}^{-1}$. The objective lens of $100 \times$ was used. The laser line used was a $660 \mathrm{~nm}$ solid state diode laser standard bandwidth version with double edge filter upgrade and the acquisition time for the data was 3 seconds. The sample was placed onto a microscope slide and was levelled off, and this was placed in the slide holder for analysis.

Samples for XPS were analysed on a Thermo VG Scientific (East Grinstead, UK) ESCALAB Mk II spectrometer, which has an XR3 twin anode X-ray source (AlK $\alpha / \mathrm{MgK} \alpha$ ) and an Alpha 110 analyser. The twin anodes AlK $\alpha$ X-ray source $(h \nu=1486.6 \mathrm{eV})$ was used at $300 \mathrm{~W}(15 \mathrm{kV} \times 20 \mathrm{~mA})$ for analyses of all samples. For all survey spectra a pass energy of $200 \mathrm{eV}$ and a step size of $0.4 \mathrm{eV}$ were used. In order to acquire $\mathrm{C} 1 \mathrm{~s}$, O1s and Ti2p high resolution spectra a pass energy of $20 \mathrm{eV}$ and a step size of $0.2 \mathrm{eV}$ were used.

The Fourier Transform Infrared spectrometer (FTIR) was used with an attenuated total reflection (ATR) accessory. A PerkinElmer Spectrum 100 FT-IR spectrometer was used in examining the samples, in a range of $400 \mathrm{~cm}^{-1}$ to $4000 \mathrm{~cm}^{-1}$, a resolution of $4 \mathrm{~cm}^{-1}$, and 4 scans per sample. For all of the samples, there were peaks present for Ti-O-Ti. In the case of the samples that contain benzoic acid (Fig. 1), there are a number of different types of binding that could be detected, e.g. for benzene ring, $\mathrm{C}=\mathrm{O}, \mathrm{C}-\mathrm{O}, \mathrm{C}-\mathrm{OH}, \mathrm{C}-\mathrm{C}, \mathrm{C}=\mathrm{C}$ and $\mathrm{O}-\mathrm{H}$.

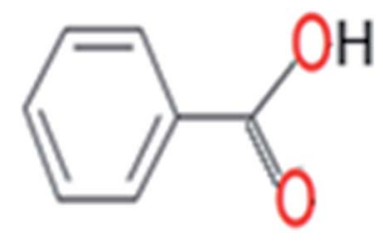

Fig. 1 Benzoic acid. 
The Brunauer-Emmett-Teller method (BET) was used for determining the specific surface area for the samples. Each powder sample was degassed at $300{ }^{\circ} \mathrm{C}$ for an hour. The adsorption isotherms were acquired at $-196.15{ }^{\circ} \mathrm{C}$. The scanning electron microscopy (SEM) (Siemens TM1000) was deployed for examining the surface morphology of the sample.

\section{Results and discussion}

The two main objectives of this study were to determine what effect this doping had on the anatase to rutile transition (ART) and investigate if that carbon was incorporated into the titania structure or if it doped onto the surface.

\section{X-ray diffraction (XRD)}

In order to determine the effect of chemical modification on the phase transition in titanium dioxide, XRD was employed. In order to determine the fraction of anatase and rutile in a sample, the intensities of the main anatase (101) and rutile (110) peaks were used for the analysis using Spurr equation (eqn (1)). All diffractograms showed only the presence of titania peaks and there were no benzoic acid peaks (one at approx. $8^{\circ}$ and two peaks at approx. 16 and $17^{\circ}$ ) present for any of the samples. ${ }^{37}$ All samples contained $100 \%$ anatase phase titania when calcined at $500{ }^{\circ} \mathrm{C}$. At $600^{\circ} \mathrm{C}$ all samples that have benzoic acid as a chemical additive contain $100 \%$ anatase, while the control sample converted to $73 \%$ rutile phase (Fig. S1†). As stated above the anatase to rutile transition occurs in pure synthetic titania between $600-700{ }^{\circ} \mathrm{C},{ }^{13,19}$ the control for this study followed this pattern as it was $100 \%$ rutile by $700{ }^{\circ} \mathrm{C}$. The samples with benzoic acid has a significant increase in the anatase phase at $700{ }^{\circ} \mathrm{C}$ when compared with the control, $1: 1$ has $50 \%$ anatase, $1: 4$ has $76 \%$ anatase and $1: 8$ has $71 \%$ (Fig. 2). By $800{ }^{\circ} \mathrm{C}$, the 1 : 1 sample had transitioned into $100 \%$ rutile while the $1: 4$ and $1: 8$ samples at the same temperature still had small amounts of anatase present (10\% and $7 \%)$, Fig. S2.† Fig. 3 shows the \% anatase for all samples. Above

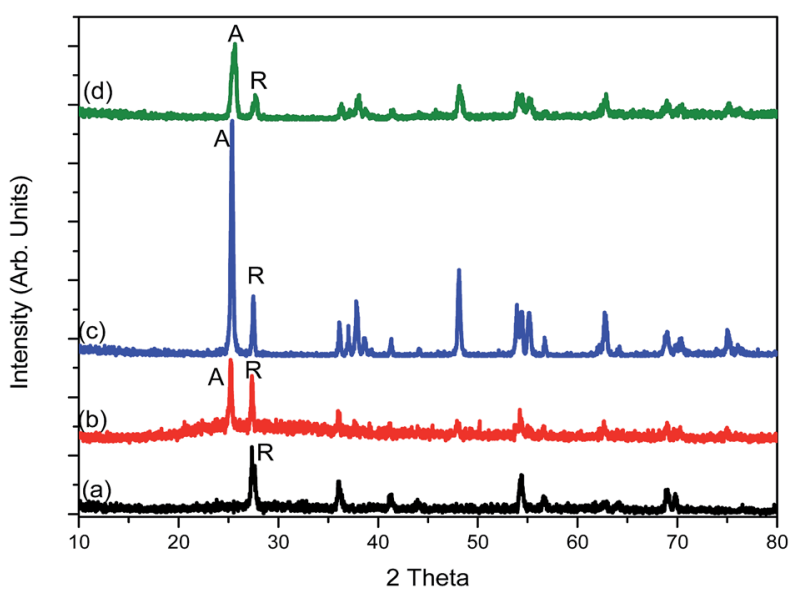

Fig. 2 XRD of all concentrations that have been calcined at $700{ }^{\circ} \mathrm{C}$. (a) Undoped $\mathrm{TiO}_{2}$ (b) $1: 1 \mathrm{TiO}_{2}$ : benzoic acid (c) $1: 4 \mathrm{TiO}_{2}$ : benzoic acid and (d) $1: 8 \mathrm{TiO}_{2}$ : benzoic acid. $\mathrm{A}=$ anatase and $\mathrm{R}=$ rutile.

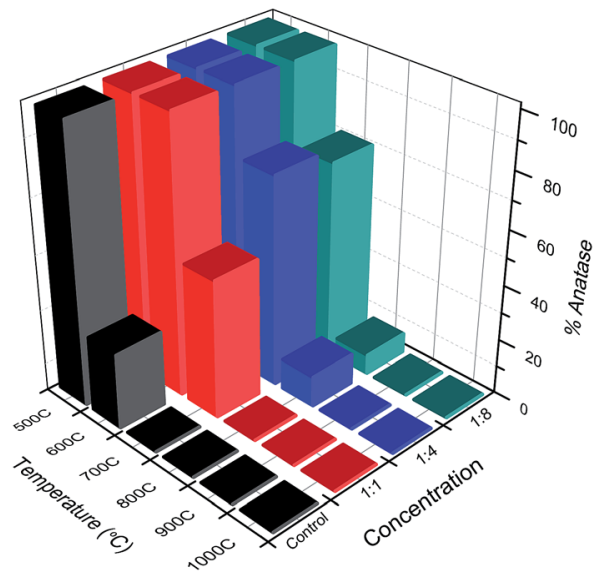

Fig. 3 Anatase present (in \%) in each of the samples at various temperatures.

$800{ }^{\circ} \mathrm{C}$ all samples are $100 \%$ rutile. These results show that using benzoic acid as a carbon dopant does inhibit the anatase to rutile transition, causing it to occur at higher temperatures than normal.

\section{Raman spectroscopy}

Raman spectroscopy was employed as a complementary tool for identifying the anatase and/or rutile phase formation at all temperatures. As with XRD, there are characteristic peaks and modes for both phases. ${ }^{\mathbf{1 0 1 2 , 3 8}}$ The only peaks on the Raman spectra, as with XRD, where those that indicate the presence of the two titania phases. The active modes for anatase are $\mathrm{A}_{1 \mathrm{~g}}$, $2 \mathrm{~B}_{1 \mathrm{~g}}$ and $3 \mathrm{E}_{\mathrm{g}}$ at $147,197,396,516$ and $638 \mathrm{~cm}^{-1} \cdot{ }^{\mathbf{1 0 , 1 2 , 3 8 - 4 1}}$ For rutile they are $A_{1 g}, B_{1 g}, B_{2 g}$ and $3 E_{g}$ at 144, 238, 446, 612 and 827 $\mathrm{cm}^{-1} \cdot{ }^{10,12,38-41}$ The results gained from Raman analysis concur with those of XRD analysis. The $1: 8 \mathrm{TiO}_{2}$ : benzoic acid sample calcined at $600{ }^{\circ} \mathrm{C}$ contains $100 \%$ anatase, the characteristic anatase peaks for Raman can be seen in this sample can be seen in Fig. 4. The $1: 8 \mathrm{TiO}_{2}$ : benzoic acid sample calcined at $900{ }^{\circ} \mathrm{C}$

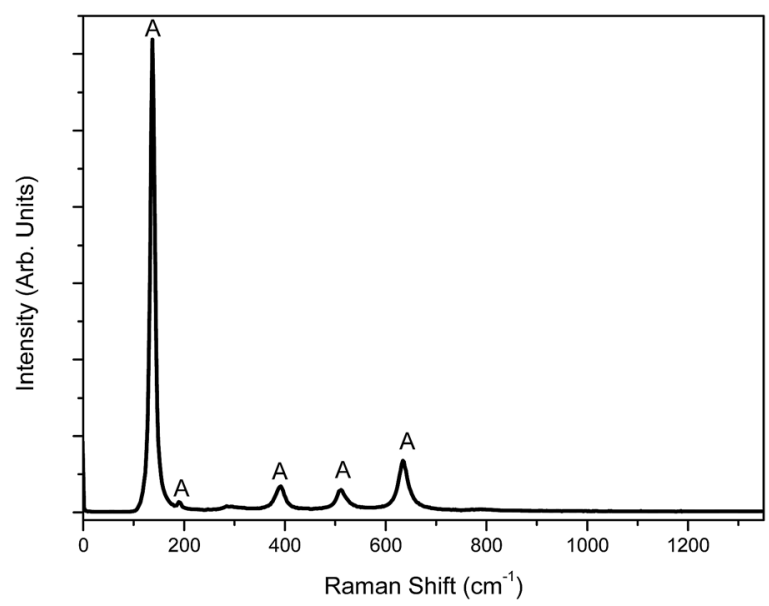

Fig. 4 Raman spectra of the $1: 8 \mathrm{TiO}_{2}$ : benzoic acid sample calcined at $600{ }^{\circ} \mathrm{C}, \mathrm{A}=$ anatase. 
contains $100 \%$ rutile; the characteristic rutile peaks for Raman can seen in this sample can be seen in Fig. 5 . When the sample is a mixed phased sample the Raman peaks for anatase and rutile will be present, see Fig. $\mathrm{S} 3 . \dagger$

\section{X-ray photoelectron spectroscopy (XPS)}

X-ray photoelectron spectroscopy (XPS) was used in order to determine the bonding/binding that was occurring for each sample. It was also employed for examining if the carbon was integrated into the titania structure or if the carbon resided on the titania surface. XPS was employed to determine the impact of precursor modification on the binding energy (eV). XPS analysis was only carried out on samples between $600-800{ }^{\circ} \mathrm{C}$. The binding energy (eV) for C1s for all four concentrations at the three temperatures remained unchanged, see Table S1. $\dagger$ The peak at $285.0 \mathrm{eV}$ is indicative of adventitious carbon $(\mathrm{C}-\mathrm{C}$, $\mathrm{C}=\mathrm{C}$ and/or $\mathrm{C}-\mathrm{H}$ bonds). ${ }^{12,23,38}$ The characteristic peak for Ti-C $(281.5 \mathrm{eV})$ was not present, which indicates that the carbon was

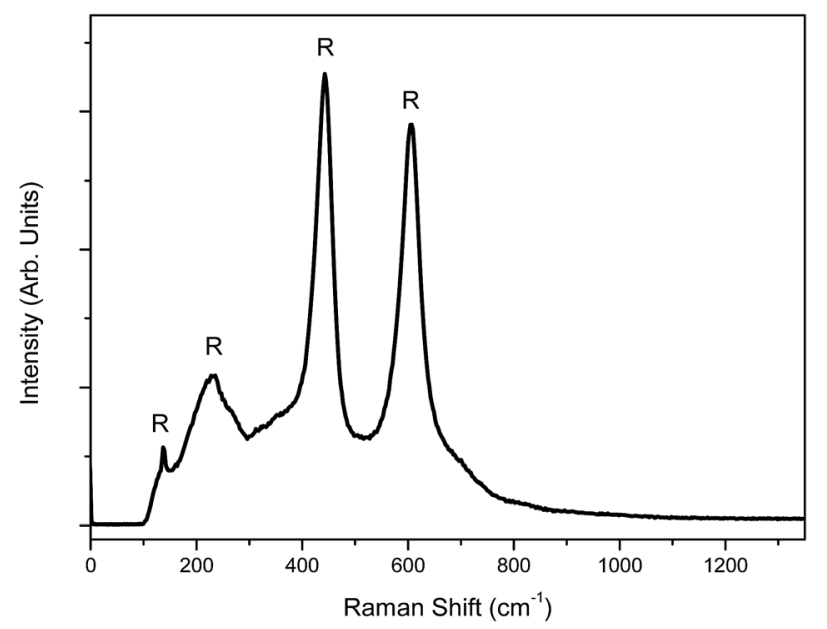

Fig. 5 Raman spectra of the $1: 8 \mathrm{TiO}_{2}$ : benzoic acid sample calcined at $900^{\circ} \mathrm{C}, \mathrm{R}=$ rutile. not doped into the $\mathrm{TiO}_{2}$ lattice but onto the $\mathrm{TiO}_{2}$ surface..$^{\mathbf{1 0 , 3 8 , 4 2}}$ When Yang et al. (2006) examined $\mathrm{N}-\mathrm{C}$ doped $\mathrm{TiO}_{2}$, they also found that there was carbon doping into the $\mathrm{TiO}_{2}$ lattice for the $\mathrm{TiO}_{2}$ films however in the films containing carbon and nitrogen it is suggest that the carbon is doped in the $\mathrm{TiO}_{2}$ films. ${ }^{43}$ There were also no peaks present for $\mathrm{C}-\mathrm{O}, \mathrm{C}=\mathrm{O}$ and carbon bonded to three oxygen, 287, 289 and $291 \mathrm{eV}$ respectively. ${ }^{33,38,44-46}$ This could mean that the benzoic acid is being burned off, FTIR supports this observation. For all concentrations, there was a slight decrease in binding energy of O1s as the temperature increased, there was a similar decrease in the binding energy of all samples for Ti2 $\mathrm{p}_{3 / 2}$ (Ti-O), ${ }^{23}$ see Fig. 6 and Table S1. $\dagger$ The slight decrease in O1s binding energy shows that the samples are oxygen rich and as the temperature increases oxygen vacancies begin to form. The slight decrease in the Ti2 $\mathrm{p}_{3 / 2}$ binding energy also demonstrates the formation of oxygen vacancies and this leads to the conversion of $\mathrm{Ti}^{4+}$ to $\mathrm{Ti}^{3+} \cdot{ }^{\mathbf{2 3 , 4 0 , 4 7}} \mathrm{In}$ a similar study, Yang et al. (2009) co-doped $\mathrm{TiO}_{2}$ with carbon and nitrogen there was such a significant decrease in Ti2 $\mathrm{p}_{3 / 2}$ that it lead to the conversion $\mathrm{Ti}^{4+}$ to $\mathrm{Ti}^{3+}$ to $\mathrm{Ti}^{2+} \cdot{ }^{43}$ This decrease in the $\mathrm{O} 1 \mathrm{~s}$ and $\mathrm{Ti} 2 \mathrm{p}_{3 / 2}$ signifies that anatase is transitioning into rutile. Fig. $\mathrm{S} 4 \uparrow$ shows the presence of $T i 2 \mathrm{p}_{1 / 2}$ peaks for the $1: 4$ sample at all temperatures. Peaks for Ti2 $\mathrm{p}_{1 / 2}$ are present in all samples between $458.6-459.0 \mathrm{eV}^{34,43}$ These peaks donates the presence of $\mathrm{Ti}$ the form of $\mathrm{TiO}_{2}$, i.e. in a tetravalent state. ${ }^{34,43}$

\section{Fourier transform infrared spectroscopy}

FTIR-ATR was used in order to examine the various bonds and shifts that are present as a result of the samples $(1: 1,1: 4$ and $1: 8)$ containing benzoic acid $\left(\mathrm{C}_{7} \mathrm{H}_{6} \mathrm{O}_{2}\right)$. Each concentration was examined when uncalcined, at $500{ }^{\circ} \mathrm{C}$ and $900{ }^{\circ} \mathrm{C}$, see Fig. S5 $\dagger$ and Table 1.

The type of binding a carboxylate group displays can be observed with the use of FTIR. ${ }^{19}$ The difference between the carboxylate stretches and the asymmetric carboxylate vibrations, $\Delta=\nu_{\text {as }}\left(\mathrm{COO}^{-}\right)-\nu_{\mathrm{s}}\left(\mathrm{COO}^{-}\right)$, is used for identifying the type of binding. ${ }^{19,48}$ The $\Delta$ for ionic carboxylate is reported to be $191 \mathrm{~cm}^{-1} .^{49}$ Bridge coordination relates to when one divalent
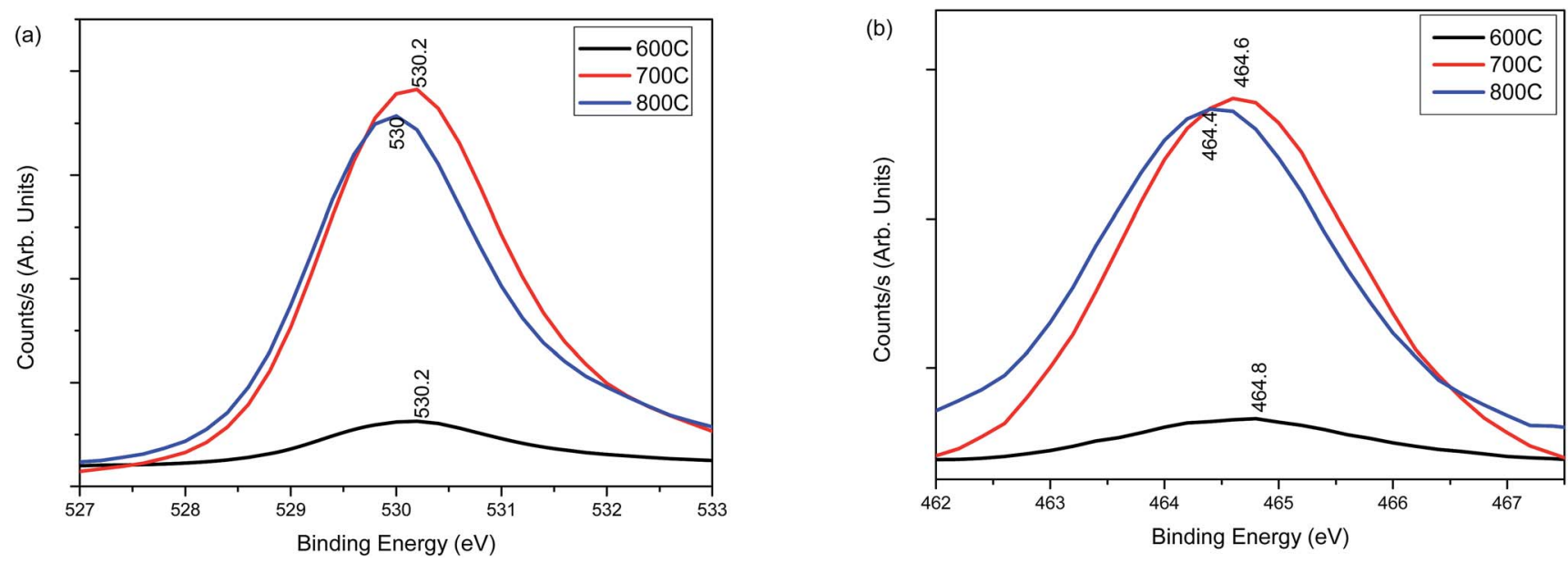

Fig. 6 XPS of $1: 4 \mathrm{TiO}_{2}$ : benzoic acid at $600{ }^{\circ} \mathrm{C}, 700{ }^{\circ} \mathrm{C}$ and $800^{\circ} \mathrm{C}$ for (a) O1s and (b) $\mathrm{Ti} 2 \mathrm{p}_{3 / 2}$. 
Table 1 FTIR results for control, $1: 1,1: 4$ and $1: 8$ at $500{ }^{\circ} \mathrm{C}$

\begin{tabular}{lll}
\hline Sample & Bond & Peak $(\mathrm{s}) \mathrm{cm}^{-1}$ (strength) \\
\hline Control & Ti-O-Ti & $515,526,547,555$ (all very weak) \\
$1: 1$ & Ti-O-Ti & 546 (weak) \\
& $\mathrm{C}-\mathrm{O}_{\text {symmetric }}$ & 1417 (weak) \\
$1: 4$ & $\mathrm{Ti}-\mathrm{O}-\mathrm{Ti}$ & 564 (very weak) \\
& Benzene ring & 1125 (weak) \\
& $\mathrm{C}-\mathrm{O}_{\text {symmetric }}$ & 1417 (medium) \\
& $\mathrm{C}-\mathrm{O}_{\text {asymmetric }}$ & 1593 (weak) \\
& $\mathrm{C}=\mathrm{O}$ & 1600 (weak) \\
& $\mathrm{Ti}-\mathrm{O}-\mathrm{Ti}$ & 530 (weak) \\
& Benzene ring & 1025 (weak) \\
& $\mathrm{C}-\mathrm{O}_{\text {symmetric }}$ & 1416 (medium) \\
& $\mathrm{C}$ rboxylate moieties & 1538 (weak) \\
& $\mathrm{C}-\mathrm{O}_{\text {asymmetric }}$ & 1590,1690 (weak)
\end{tabular}

titanium cation binds to one of the oxygens in the $\mathrm{COO}^{-}$group, another to the remaining oxygen. This results in the ionic moiety occurring at the same place as the asymmetric stretch. ${ }^{19,48,50}$ There are four pairs of electrons in the carboxylate functional group (Fig. 7) that have the ability to react with the titanium. ${ }^{19}$ The lone pair of electrons are pushed apart at an angle of $120^{\circ}$, they are labelled syn and anti-lone pair of electrons depending on their position, Fig. 7.

Many studies report that when $\Delta\left(\mathrm{COO}^{-}\right)_{\text {formate }}$ complex $\leq$ $\Delta\left(\mathrm{COO}^{-}\right)_{\text {sodium salt }}$ there is the formation of the bidentate bridging carboxylate. ${ }^{19,51-55}$ Nolan et al. (2009) suggested that the titanium centre will interact with the formate group in the bidentate bridging mode, in syn-syn or syn-anti formation. ${ }^{19} \mathrm{It}$ is noted that the benzoate group reacts with the Ti centre in the same manner as the formate group. However, due to the bulky nature of the benzene ring and steric hindrance, it is anticipated that syn-syn formation (Fig. 8(a)) will be favoured over the syn-anti formation, Fig. 8(b).

When control samples were examined with FTIR-ATR, the only peaks that were present were those for Ti-O-Ti $(570-$ $430 \mathrm{~cm}^{-1}$ ). The peaks for the three temperatures all occurred at similar points: uncalcined materials contained peaks at $515 \mathrm{~cm}^{-1}$ and $527 \mathrm{~cm}^{-1}$ with weak signal and $538 \mathrm{~cm}^{-1}$ and 547 $\mathrm{cm}^{-1}$ with very weak signal; $500{ }^{\circ} \mathrm{C}$ contained peaks of 515 $\mathrm{cm}^{-1}, 526 \mathrm{~cm}^{-1}, 547 \mathrm{~cm}^{-1}$ and $554 \mathrm{~cm}^{-1}$ all of very weak signal and the samples at $900{ }^{\circ} \mathrm{C}$ contained peaks at $515 \mathrm{~cm}^{-1}, 523$ $\mathrm{cm}^{-1}, 531 \mathrm{~cm}^{-1}$ and $546 \mathrm{~cm}^{-1}$ all of weak signal. ${ }^{56}$

As with the control, when examined with FTIR all $1: 1$ samples contained low Ti-O-Ti peaks, uncalcined at $548 \mathrm{~cm}^{-1}$, $500{ }^{\circ} \mathrm{C}$ at $546 \mathrm{~cm}^{-1}$ and $900{ }^{\circ} \mathrm{C}$ at $537 \mathrm{~cm}^{-1}$. The uncalcined

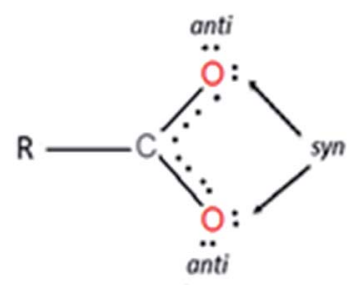

Fig. 7 Carboxylate functional group.
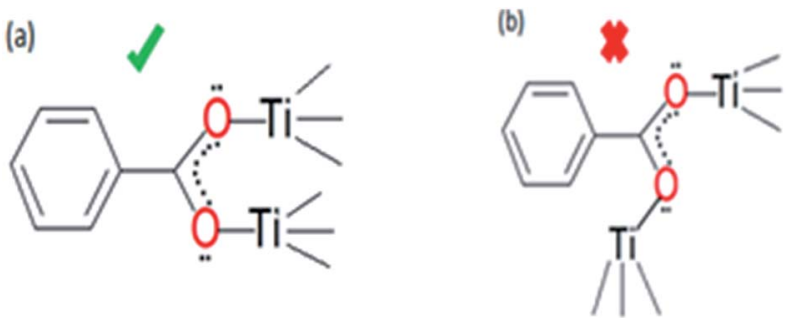

Fig. 8 Bidentate bridging modes of the benzoate group and $\mathrm{TiO}_{2}$ (a) syn-syn and (b) syn-anti.

sample was the only one at $1: 1$ that a small peak could be observed for a benzene ring, at $1026 \mathrm{~cm}^{-1}$ and $1071 \mathrm{~cm}^{-1}$, the absence of this peak for the calcined sample could mean that the benzene ring has broken into simple hydrocarbon chains. It should be noted that the peak at $1286 \mathrm{~cm}^{-1}$ in the uncalcined sample indicates a carboxyl group $(\mathrm{COOH})$ and is not present in the other samples. The uncalcined sample contains a medium $\mathrm{C}-\mathrm{O}$ symmetric stretch $\left(1411 \mathrm{~cm}^{-1}\right)$, while $500{ }^{\circ} \mathrm{C}$ shows a weak $\mathrm{C}-\mathrm{O}$ symmetric stretch $\left(1417 \mathrm{~cm}^{-1}\right){ }^{19,48}$ This is not present at $900{ }^{\circ} \mathrm{C}$. The remaining peaks on the uncalcined spectra, 1515 and $1596 \mathrm{~cm}^{-1}$ and $1693 \mathrm{~cm}^{-1}$, accounting for low asymmetric $\mathrm{C}-\mathrm{O}$ and $\mathrm{C}=\mathrm{O}$ stretches, respectively. ${ }^{19,48}$

All 1:4 samples (Fig. S4†) contained very weak Ti-O-Ti peaks, uncalcined at $559 \mathrm{~cm}^{-1}, 500{ }^{\circ} \mathrm{C}$ at $564 \mathrm{~cm}^{-1}$ and $900{ }^{\circ} \mathrm{C}$ at $569 \mathrm{~cm}^{-1}$. The uncalcined and $500^{\circ} \mathrm{C}$ samples both showed the presence of benzene ring(s), with a medium peak at $1025 \mathrm{~cm}^{-1}$ for uncalcined and a weak peak at $1125 \mathrm{~cm}^{-1}$ for the sample calcined to $500{ }^{\circ} \mathrm{C}$. There is also peak at $1289 \mathrm{~cm}^{-1}$ in the uncalcined sample for a carboxyl group $(\mathrm{COOH})$ and one at 1319 $\mathrm{cm}^{-1}$ that indicates the presence of $\mathrm{C}-\mathrm{OH}$ and is not present in the other samples. The uncalcined sample contains a strong $\mathrm{C}-\mathrm{O}$ symmetric stretch $\left(1403 \mathrm{~cm}^{-1}\right)$, while $500{ }^{\circ} \mathrm{C}$ shows a medium $\mathrm{C}-\mathrm{O}$ symmetric stretch $\left(1417 \mathrm{~cm}^{-1}\right)$. This is not present at $900{ }^{\circ} \mathrm{C}$. There are also peaks that show weak asymmetric $\mathrm{C}-\mathrm{O}$ (uncalcined $-1593 \mathrm{~cm}^{-1}$ and $500^{\circ} \mathrm{C}-1593 \mathrm{~cm}^{-1}$ ) and $\mathrm{C}=\mathrm{O}$ (both $-1600 \mathrm{~cm}^{-1}$ ) stretches.

The FTIR results for the $1: 8$ samples are discussed in detail in the ESI. $\dagger$

\section{Brunauer-Emmett-Teller method (BET)}

BET analysis was performed in order to determine the surface area and porosity of the sample. The surface area of the samples was $30.7,15.8,40.4$ and $21.2 \mathrm{~m}^{2} \mathrm{~g}^{-1}$ for the control, $1: 1,1: 4$ and $1: 8$, respectively. The porosity for all samples were very similar varying only by $\pm 1 \AA, 20.72 \AA$ (control), $20.63 \AA(1: 1)$, $20.76 \AA(1: 4)$ and $20.79 \AA(1: 8)$.

\section{Scanning electron microscope (SEM)}

SEM analysis was employed in order to determine the morphology of each of the sample. These analyses showed that the samples are highly agglomerated and no specific shapes were identified. A typical SEM image is shown in the ESI (Fig. S6†). 
From XRD and Raman spectroscopy analysis it was shown that modifying $\mathrm{TiO}_{2}$ with benzoic acid increased the anatase to rutile transition temperature. Nolan et al. (2009) found that increasing the amount of water causes the resulting sol to become less acidic during the hydrolysis of TTIP. ${ }^{19,57-59}$ This minimised the chelation effect, which weakened gel network and consequently lowers the transition temperature. ${ }^{\mathbf{1 9 , 5 7 - 6 0}}$ It has also been noted Kung et al. (1996) that the size and number of branches within the gel network directly effects the porosity of the gel. ${ }^{60}$ This then has an impact on resulting material's surface area, porosity and thermal stability during calcination. ${ }^{60}$ The current study kept the volume of water constant and the addition of increasing amounts benzoic acid caused the sol to become increasingly acidic. It can be concluded that the increase in acidity causes the chelation effect to increase, thus strengthening the gel network and causing the anatase to rutile transition to occur at elevated temperatures. ${ }^{19}$ FTIR showed the presence of the characteristic bonds for benzoic acid $(\mathrm{C}-\mathrm{O}, \mathrm{C}=$ $\mathrm{O}, \mathrm{COOH}$, benzene) to various degree depending on the concentration of doped benzoic acid (1:1,1:4, or $1: 8)$ and the calcination temperature (uncalcined, 500 to $1000{ }^{\circ} \mathrm{C}$ ). FTIR analysis, along with XPS, revealed that the carbon was on the $\mathrm{TiO}_{2}$ surface. This is indicated by the fact only the peaks for Ti$\mathrm{O}-\mathrm{Ti}$ are present on the FTIR spectra. The $1: 4$ sample proved to be the optimum sample for all analysis.

\section{Conclusions}

The current investigation examined the effect that chemically modifying $\mathrm{TiO}_{2}$ with benzoic acid (at various concentrations) had on the anatase to rutile transition temperature, using XRD and Raman spectroscopy. Whether the carbon was included in the titania structure or if the carbon sat on the surface of the titania was examined with FTIR and XPS. There were large amounts of anatase present at $700{ }^{\circ} \mathrm{C}$ in the $1: 1,1: 4$ and $1: 8$ doped samples $(50,76,71 \%$ anatase). There was also anatase present in $1: 4$ and $1: 8$ at $800{ }^{\circ} \mathrm{C}, 11 \%$ and $7 \%$ respectively. These results were confirmed when the samples were analysed with Raman spectroscopy. This is an increase on the anatase to rutile transition temperature; rutile is normally formed fully at $700{ }^{\circ} \mathrm{C}$. With the use of XPS and FTIR it was determined that the carbon was present on the surface on the titania.

\section{Acknowledgements}

Ciara Byrne wishes to acknowledge the Institute of Technology Sligo President's Bursary for providing financial support.

\section{References}

1 S. G. Kumar and K. S. R. K. Rao, Nanoscale, 2014, 6, 1157411632.

2 K. Thamaphat, P. Limsuwan and B. Ngotawornchai, Kasetsart J.: Nat. Sci., 2008, 42, 357-361.

3 M. B. Fisher, D. A. Keane, P. Fernandez-Ibanez, J. Colreavy, S. J. Hinder, K. G. McGuigan and S. C. Pillai, Appl. Catal., $B, 2013,130,8-13$.
4 S. Banerjee, S. C. Pillai, P. Falaras, K. E. O'Shea, J. A. Byrne and D. D. Dionysiou, J. Phys. Chem. Lett., 2014, 5, 2543-2554.

5 O. Carp, C. L. Huisman and A. Reller, Prog. Solid State Chem., 2004, 32, 33-177.

6 C. Zhao, M. Pelaez, D. D. Dionysiou, S. C. Pillai, J. A. Byrne and K. E. O'Shea, Catal. Today, 2014, 224, 70-76.

7 V. Etacheri, C. Di Valentin, J. Schneider, D. Bahnemann and S. C. Pillai, J. Photochem. Photobiol., C, 2015, 25, 1-29.

8 D. A. Hanaor and C. C. Sorrell, J. Mater. Sci., 2011, 46, 855874.

9 A. Okasha, F. Gomaa, H. Elhaes, M. Morsy, S. El-Khodary, A. Fakhry and M. Ibrahim, Spectrochim. Acta, Part A, 2015, 136, 504-509.

10 S. C. Pillai, P. Periyat, R. George, D. E. McCormack, M. K. Seery, H. Hayden, J. Colreavy, D. Corr and S. J. Hinder, J. Phys. Chem. C, 2007, 111, 1605-1611.

11 N. T. Nolan, M. K. Seery, S. J. Hinder, L. F. Healy and S. C. Pillai, J. Phys. Chem. C, 2010, 114, 13026-13034.

12 V. Etacheri, M. K. Seery, S. J. Hinder and S. C. Pillai, Chem. Mater., 2010, 22, 3843-3853.

13 M. K. Seery, R. George, P. Floris and S. C. Pillai, J. Photochem. Photobiol., A, 2007, 189, 258-263.

14 N. S. Leyland, J. Podporska-Carroll, J. Browne, S. J. Hinder, B. Quilty and S. C. Pillai, Sci. Rep., 2016, 6, 24770.

15 Y. Hu, H. L. Tsai and C. L. Huang, J. Eur. Ceram. Soc., 2003, 23, 691-696.

16 R. F. de Farias, C. C. Silva and T. A. Restivo, J. Serb. Chem. Soc., 2005, 70, 675-679.

17 P. Periyat, S. C. Pillai, D. E. McCormack, J. Colreavy and S. J. Hinder, J. Phys. Chem. C, 2008, 112, 7644-7652.

18 E. F. Heald and C. W. Weiss, Am. Mineral., 1972, 57, 10-23.

19 N. T. Nolan, M. K. Seery and S. C. Pillai, J. Phys. Chem. C, 2009, 113, 16151-16157.

20 C. Byun, J. W. Jang, I. T. Kim, K. S. Hong and B. W. Lee, Mater. Res. Bull., 1997, 32, 431-440.

21 A. Markowska-Szczupak, K. Ulfig and A. Morawski, Catal. Today, 2011, 169, 249-257.

22 M. Pelaez, N. T. Nolan, S. C. Pillai, M. K. Seery, P. Falaras, A. G. Kontos, P. S. Dunlop, J. W. Hamilton, J. A. Byrne and K. O'Shea, Appl. Catal., B, 2012, 125, 331-349.

23 V. Etacheri, M. K. Seery, S. J. Hinder and S. C. Pillai, Adv. Funct. Mater., 2011, 21, 3744-3752.

24 R. Fagan, D. E. McCormack, D. D. Dionysiou and S. C. Pillai, Mater. Sci. Semicond. Process., 2015, 42, 2-14.

25 M. Gopal, W. M. Chan and L. De Jonghe, J. Mater. Sci., 1997, 32, 6001-6008.

26 C. Suresh, V. Biju, P. Mukundan and K. Warrier, Polyhedron, 1998, 17, 3131-3135.

27 C. Rao, A. Turner and J. Honig, J. Phys. Chem. Solids, 1959, 11, 173-175.

28 D. J. Reidy, J. D. Holmes, C. Nagle and M. A. Morris, J. Mater. Chem., 2005, 15, 3494-3500.

29 K. V. Baiju, C. P. Sibu, K. Rajesh, P. K. Pillai, P. Mukundan, K. G. K. Warrier and W. Wunderlich, Mater. Chem. Phys., 2005, 90, 123-127.

30 R. Fagan, D. W. Synnott, D. E. McCormack and S. C. Pillai, Appl. Surf. Sci., 2016, 371, 447-452. 
31 R. Fagan, D. E. McCormack, S. J. Hinder and S. C. Pillai, Mater. Des., 2016, 96, 44-53.

32 H. Irie, Y. Watanabe and K. Hashimoto, Chem. Lett., 2003, 32, 772-773.

33 S. Sakthivel and H. Kisch, Angew. Chem., Int. Ed., 2003, 42, 4908-4911.

34 R. Fagan, D. E. McCormack, S. J. Hinder and S. C. Pillai, Materials, 2016, 9, 286.

35 H. Wang and J. Lewis, J. Phys.: Condens. Matter, 2005, 18, 421.

36 R. A. Spurr and H. Myers, Anal. Chem., 1957, 29, 760-762.

37 S. A. Maruyama, F. d. S. Lisboa, L. P. Ramos and F. Wypych, Quim. Nova, 2012, 35, 1510-1516.

38 V. Etacheri, G. Michlits, M. K. Seery, S. J. Hinder and S. C. Pillai, ACS Appl. Mater. Interfaces, 2013, 5, 1663-1672.

39 T. Ohsaka, F. Izumi and Y. Fujiki, J. Raman Spectrosc., 1978, 7, 321-324.

40 H. Berger, H. Tang and F. Lévy, J. Cryst. Growth, 1993, 130, 108-112.

41 H. Tang, K. Prasad, R. Sanjines, P. Schmid and F. Levy, J. Appl. Phys., 1994, 75, 2042-2047.

42 Z. Shi, X. Ye, K. Liang, S. Gu and F. Pan, J. Mater. Sci. Lett., 2003, 22, 1255-1258.

43 J. Yang, H. Bai, X. Tan and J. Lian, Appl. Surf. Sci., 2006, 253, 1988-1994.

44 V. Etacheri, U. Geiger, Y. Gofer, G. A. Roberts, I. C. Stefan, R. Fasching and D. Aurbach, Langmuir, 2012, 28, 6175-6184.

45 V. Etacheri, O. Haik, Y. Goffer, G. A. Roberts, I. C. Stefan, R. Fasching and D. Aurbach, Langmuir, 2011, 28, 965-976.

46 O. Akhavan, E. Ghaderi and A. Akhavan, Biomaterials, 2012, 33, 8017-8025.
47 D. Dvoranová, V. Brezová, M. Mazúr and M. A. Malati, Appl. Catal., B, 2002, 37, 91-105.

48 V. Zeleňák, Z. Vargová and K. Györyová, Spectrochim. Acta, Part A, 2007, 66, 262-272.

49 X.-h. Guan, G.-h. Chen and C. Shang, J. Environ. Sci., 2007, 19, 438-443.

50 M. Nara, M. Tasumi, M. Tanokura, T. Hiraoki, M. Yazawa and A. Tsutsumi, FEBS Lett., 1994, 349, 84-88.

51 K. Nakamoto, Infrared and Raman spectra of inorganic and coordination compounds, Wiley Online Library, 1986.

52 D. Czakis-Sulikowska, A. Czylkowska and A. Malinowska, J. Therm. Anal. Calorim., 2002, 67, 667-678.

53 G. Deacon and R. Phillips, Coord. Chem. Rev., 1980, 33, 227250.

54 W. Lewandowski, M. Kalinowska and H. Lewandowska, J. Inorg. Biochem., 2005, 99, 1407-1423.

55 B. Manhas and A. Trikha, J. Indian Chem. Soc., 1982, 59, 315319.

56 T. Bezrodna, T. Gavrilko, G. Puchkovska, V. Shimanovska, J. Baran and M. Marchewka, J. Mol. Struct., 2002, 614, 315324.

57 R. Urlaub, U. Posset and R. Thull, J. Non-Cryst. Solids, 2000, 265, 276-284.

58 A. Verma, S. Samanta, A. Bakhshi and S. Agnihotry, Sol. Energy Mater. Sol. Cells, 2005, 88, 47-64.

59 C. Guillard, B. Beaugiraud, C. Dutriez, J.-M. Herrmann, H. Jaffrezic, N. Jaffrezic-Renault and M. Lacroix, Appl. Catal., B, 2002, 39, 331-342.

60 H. H. Kung and E. I. Ko, Chem. Eng. J. Biochem. Eng. J., 1996, 64, 203-214. 